\title{
Laparoscopic management of cornual heterotopic pregnancy with the use of Harmonic $\mathrm{ACE}{ }^{\circledR}$ - a case report
}

\author{
Sonia Chachan $\cdot$ N. Waters $\cdot$ A. Kent
}

Received: 3 August 2009 / Accepted: 15 October 2009/Published online: 17 November 2009

(C) Springer-Verlag 2009

\begin{abstract}
Heterotopic pregnancy is the simultaneous coexistence of both intrauterine and extrauterine pregnancies. Cornual heterotopic pregnancies can cause catastrophic haemorrhage because of their location. Available evidence suggests that they have usually been managed surgically by laparotomy and cornual resection, few were managed medically and two expectantly. Of the surgical group, only three underwent laparoscopic management. We report the first case of successful management of cornual heterotpic pregnancy by Harmonic ACE® and a favourable outcome of the intrauterine pregnancy.
\end{abstract}

Keywords Cornual · Heterotopic · Laparoscopy Ultracision $^{\circledR}$

\section{Introduction}

Heterotopic pregnancy is the simultaneous coexistence of both intrauterine and extrauterine pregnancies. The universal quotation of incidence of heterotopic pregnancy of one in 30,000 comes from Devoe and Pratt (1948) [1]. Since then, a rise in incidence has been documented due to the increase in use of artificial reproductive technologies (ART) and also increased incidence of pelvic inflammatory diseases.

\section{S. Chachan $(\bowtie)$}

Department of Gynaecology, Royal Surrey County Hospital, Guildford, Surrey GU2 7XX, UK

e-mail: soniac@doctors.org.uk

\section{N. Waters $\cdot$ A. Kent}

Department of Gynaecology,

Institution: Minimal Access Therapy Training Unit,

Post Graduate Medical School, University of Surrey,

Manor Park, Guildford, Surrey GU2 7WG, UK
The incidence of heterotopic pregnancy after ART seems to be as high as one in 100 to one in 500 [2-5]. The incidence of cornual heterotopic pregnancy has been estimated as one in 3,600 IVF pregnancies [6]. There is no known incidence of cornual heterotopic pregnancy following ovulation induction with clomiphene citrate but an incidence of one in 900 [7] has been reported for heterotopic pregnancy in general with this drug. Alongside intrauterine pregnancy, the location of heterotopic pregnancies may be abdominal [8], bilateral tubal [9], twin gestation in the tube [3], bilateral simultaneous tubal sextuplet [10] and cornual [11].

The term cornual pregnancy is sometimes used synonymously with interstitial pregnancy. Cornual pregnancy implants in the muscular interstitial part of the fallopian tube. This allows the pregnancy to grow and distend and usually develop into the second trimester. Rupture of this pregnancy can result in catastrophic haemorrhage in up to $2 \%$ cases requiring laparotomy and even hysterectomy [11-13].

An early diagnosis and management has become possible due to advances in ultrasound resolution. The ultrasound picture of cornual heterotopic pregnancy shows two gestational sacs separated by a thick bridge of myometrium. The specific feature of cornual pregnancy is that the position of chorionic sac is separate and is more than $1 \mathrm{~cm}$ from the most lateral edge of the uterine cavity [14]. The management of cornual heterotopic pregnancy poses clinical and ethical dilemma because of coexisting intrauterine pregnancy and the history of infertility. Traditionally cornual pregnancies have been managed by laparotomy by either cornual resection or hysterectomy for uncontrollable haemorrhage. However, cornual pregnancies have been successfully managed laparoscopically. 


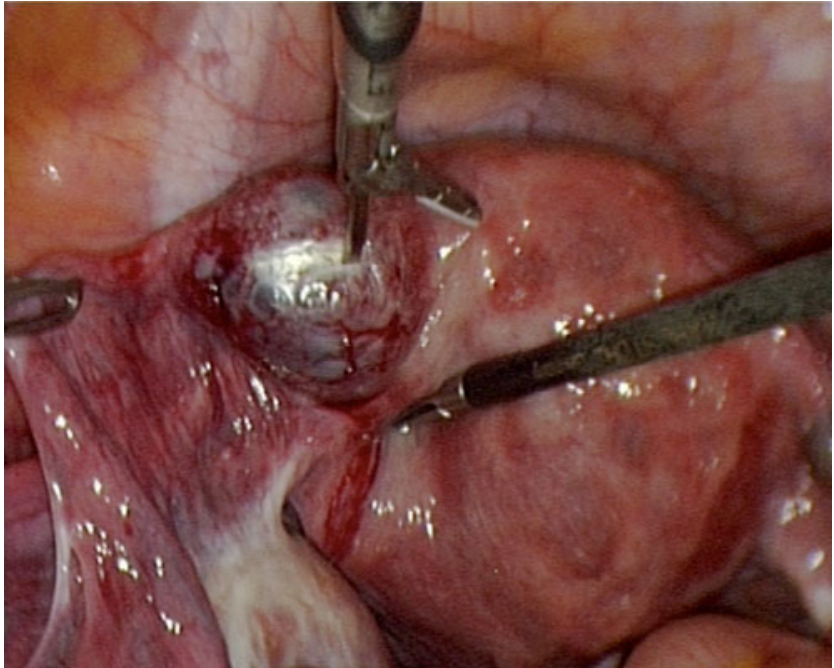

Fig. 1 Left cornual ectopic being shelled out by Harmonic $\mathrm{ACE}^{\circledR}$

There are 48 published cases of cornual heterotopic pregnancy [6, 15-25]. Only seven were from spontaneous conception, all others were from some form of assisted reproduction techniques. They were managed mainly surgically by laparotomy and cornual resection, few were managed medically and two expectantly. Of the surgical group, only three underwent laparoscopic management $[15,24,25]$.

\section{Case report}

In this case report, we present a case of cornual heterotopic pregnancy managed laparoscopically by Harmonic ACE® with excellent outcome. Our patient was a 36-year-old woman, gravida 3 . She had one previous full term spontaneous vaginal delivery and one early miscarriage.

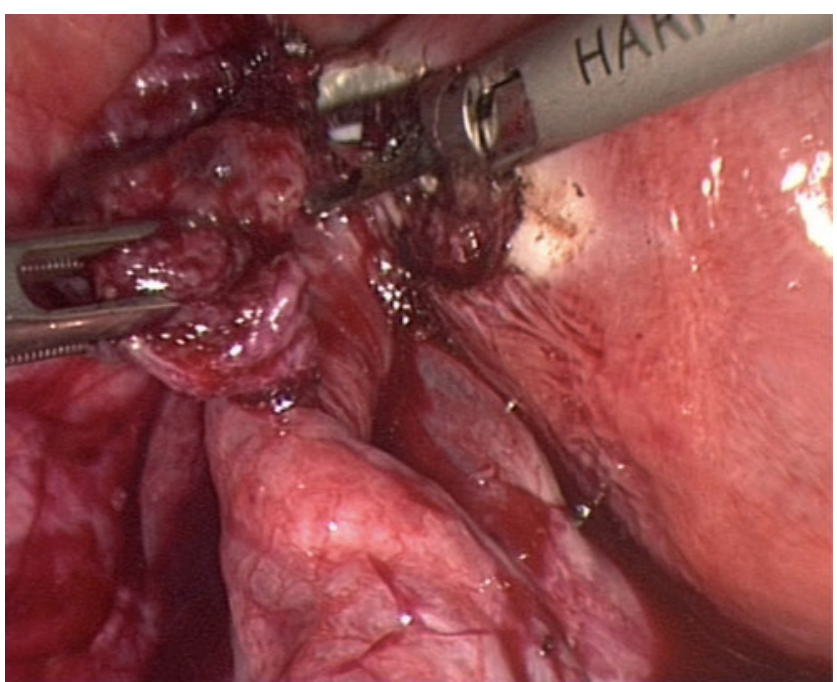

Fig. 2 Dissection continued

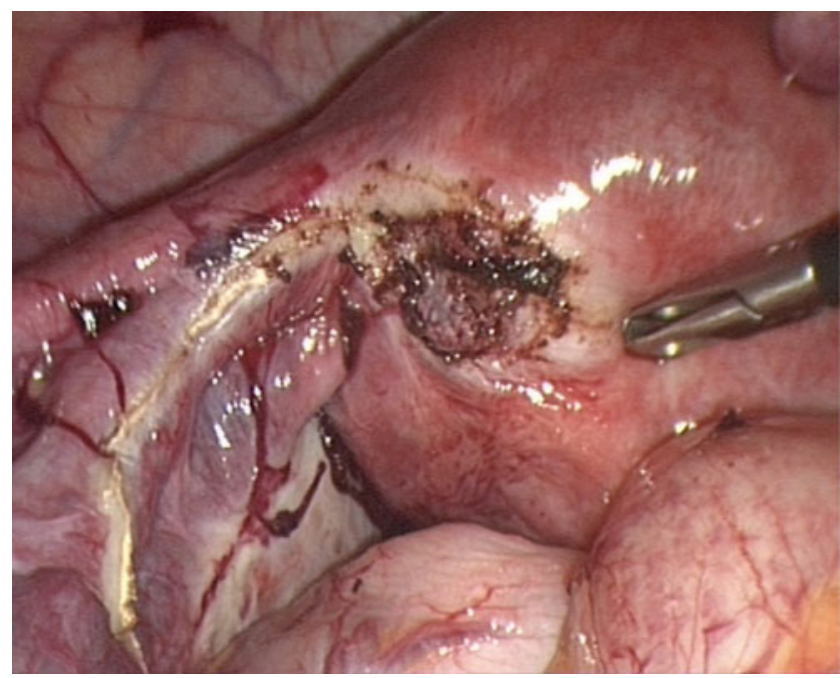

Fig. 3 Cornual pregnancy along with the left tube removed

She also had a history of secondary infertility for 2 years prior to this pregnancy. She had regular periods with ovulatory cycles and patent fallopian tubes confirmed on hysterosalphingogram. She was prescribed clomiphene citrate for unexplained infertility and conceived in the third cycle. She had no known risk factors for ectopic pregnancy. She was seen in the early pregnancy clinic for pain in the left iliac fossa with a positive pregnancy test. Transvaginal ultrasound scan (TVS) revealed a viable intrauterine pregnancy with crown rump length (CRL) of $9.8 \mathrm{~mm}$ corresponding to 7 weeks of gestation. A second gestational sac was seen in the left cornual region of the uterus. It also had a yolk sac with foetal echoes with heart action with a CRL of $8.2 \mathrm{~mm}$, corresponding to 6 weeks and 5 days. A diagnosis of intrauterine pregnancy with coexisting cornual pregnancy was made. We decided to resect the cornual

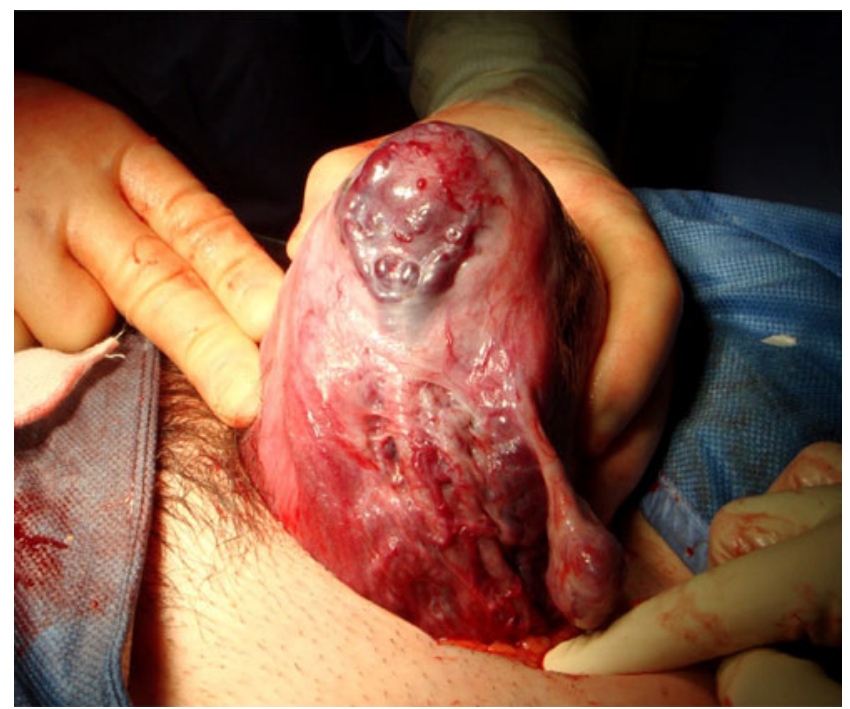

Fig. 4 Left cornu at caesarean section 
pregnancy laparoscopically and allow the intrauterine pregnancy to continue after counselling the patient about the risks involved.

At laparoscopy, a $4 \times 4 \mathrm{~cm}$ left cornual ectopic pregnancy was identified. The other tube looked normal. There were filmy adhesions surrounding the liver suggesting FitzHugh-Curtis syndrome. Using Harmonic $\mathrm{ACE}^{\circledR}$ shears, the left cornual ectopic including the entire left fallopian tube was excised with minimal blood loss (see Figs. 1, 2 and 3). The uterine cavity was not breached. Peritoneal washout was carried out with heparinised saline. The patient had a short postoperative recovery and was discharged the next day. The intrauterine pregnancy was closely monitored with regular ultrasound scans for foetal wellbeing. An elective caesarean section was performed at 38 weeks and a live male baby weighing $3,821 \mathrm{~g}$ was delivered. The operation was uncomplicated. The site of the previous cornual ectopic pregnancy was very vascular but intact (see Fig. 4). The patient made an uneventful recovery and discharged home on day 3.

\section{Discussion}

Cornual heterotopic pregnancies are not as rare as previously thought. Advancement in TVS and colour flow Doppler and MRI and establishment of early pregnancy assessment units have made immense contribution to diagnosing this condition before catastrophic haemorrhage in many cases. Early diagnosis, available surgical expertise and patient choice remain the mainstay of management of heterotopic pregnancies.

Medical management of heterotopic pregnancy has certain disadvantages as the available agents used i.e. methotrexate and prostaglandins are contraindicated in viable intrauterine pregnancies and result in high miscarriage rate. It is also difficult to monitor the resolution of the cornual pregnancy after medical management because of the increased $\beta \mathrm{hCG}$ of the ongoing intrauterine pregnancy. However, there is a possibility of selective feticide by injection of $0.5 \mathrm{~mL}$ of $15 \%$ potassium chloride into the foetal heart [23]. This treatment does not have the disadvantages mentioned above.

Review of current literature suggests a better outcome with surgical techniques especially with laparoscopy if expertise is available. Sherer et al. [24] reported a ruptured right interstitial pregnancy which was managed by resection with endo-GIA staples. The intrauterine pregnancy went on to deliver at 33 weeks by emergency lower segment caesarean section. Vilos et al. [25] reported cornual heterotopic pregnancy which was managed laparoscopically after ligation with endoloop and resection with $\mathrm{CO} 2$ laser. The patient delivered vaginally at term. Pasic et al. [15] described laparoscopic management using unipolar scissors to incise the cornual pregnancy, evacuating it and controlling the haemostasis with combination of unipolar and bipolar energy. The patient had an elective caesarean section at 38 weeks. Our patient was also delivered by elective caesarean section because we could not establish the integrity of the cornu and if it would withstand labour. Vaginal delivery however has been reported in the literature in similar situation [25].

To date in our unit, we have treated three cases of cornual ectopic with Harmonic $\mathrm{ACE}^{\circledR}$ but only this one was a heterotopic pregnancy. One of them had simultaneous sterilisation of the other tube and was uneventful. The other patient fell pregnant just 3 months after surgery and had perforation of the affected cornua at 12 weeks of pregnancy with miscarriage and needed evacuation of the uterus under laparoscopic control. The cornua was repaired simultaneously.

The harmonic scalpel is becoming increasingly popular in gynaecological surgery in recent times. It uses ultrasound energy which operates at lower temperatures compared with electrosurgery, and has simultaneous cutting and coagulating properties with minimum lateral spread and no production of smoke, only a fine mist of water or fat droplets. Harmonic ACE® therefore allows a minimally invasive surgical management in complicated cases such as this. It is a multifunctional tool combining dissection, coagulation and cutting with minimum need for change of equipment. It causes little lateral thermal spread and eliminates the danger of electrical injuries and would appear to be safe to use in cases with concurrent intrauterine pregnancy.

\section{References}

1. De VR, Pratt JH (1948) Simultaneous intrauterine and extrauterine pregnancy. Am J Obstet Gynecol 56(6):1119-1126

2. In vitro fertilization-embryo transfer (IVF-ET) (1992) in the United States: 1990 results from the IVF-ET Registry. Medical Research International. Society for Assisted Reproductive Technology (SART), The American Fertility Society. Fertil Steril 57(1):15-24

3. Goldman GA, Fisch B, Ovadia J, Tadir Y (1992) Heterotopic pregnancy after assisted reproductive technologies. Obstet Gynecol Surv 47(4):217-221

4. Lund PR, Sielaff GW, Aiman EJ (1989) In vitro fertilization patient presenting in hemorrhagic shock caused by unsuspected heterotopic pregnancy. Am J Emerg Med 7(1):49-53

5. Molloy D, Deambrosis W, Keeping D, Hynes J, Harrison K, Hennessey J (1990) Multiple-sited (heterotopic) pregnancy after in vitro fertilization and gamete intrafallopian transfer. Fertil Steril 53(6): 1068-1071

6. Habana A, Dokras A, Giraldo JL, Jones EE (2000) Cornual heterotopic pregnancy: contemporary management options. Am J Obstet Gynecol 182(5):1264-1270

7. Honarbakhsh A, Khoori E, Mousavi S (2008) Heterotopic pregnancy following ovulation induction by Clomiphene and a healthy live birth: a case report. J Med Case Reports 2:390 
8. Abdalla HI, Ahuja KK, Morris N, Lynn J (1986) Combined intraabdominal and intrauterine pregnancies after gamete intrafallopian transfer. Lancet 2(8516):1153-1154

9. Olive DL, Taylor N, Cothran GE, Schenken RS (1988) Gamete intrafallopian transfer (GIFT) complicated by bilateral ectopic pregnancy. Fertil Steril 49(4):719-720

10. Chang CC, Wu TH, Tsai HD, Lo HY (1998) Bilateral simultaneous tubal sextuplets: pregnancy after in-vitro fertilization-embryo transfer following salpingectomy. Hum Reprod 13(3):762-765

11. Bisca BV, Felder ME (1960) Coexistent interstitial and intrauterine pregnancy following homolateral salpingo-oophorectomy: report of a case. Am J Obstet Gynecol 79:263-265

12. Lau S, Tulandi $T$ (1999) Conservative medical and surgical management of interstitial ectopic pregnancy. Fertil Steril 72 (2):207-215

13. Rock J, Thompson J (2003) Telinde's Operative Gynecology. Lippincott-Raven, Philadelphia

14. Timor-Tritsch IE, Monteagudo A, Matera C, Veit CR (1992) Sonographic evolution of cornual pregnancies treated without surgery. Obstet Gynecol 79(6):1044-1049

15. Pasic RP, Hammons G, Gardner JS, Hainer M (2002) Laparoscopic treatment of cornual heterotopic pregnancy. J Am Assoc Gynecol Laparosc 9(3):372-375

16. Divry V, Hadj S, Bordes A, Genod A, Salle B (2007) Case of progressive intrauterine twin pregnancy after surgical treatment of cornual pregnancy. Fertil Steril 87(1):190

17. van der Weiden RM, Karsdorp VH (2005) Recurrent cornual pregnancy after heterotopic cornual pregnancy successfully treated with systemic methotrexate. Arch Gynecol Obstet 273(3):180-181
18. Lam PM, Lok IH, Yip SK (2004) Two cases of heterotopic cornual pregnancy with initially missed diagnosis. Aust NZ J Obstet Gynaecol 44(3):256-259

19. Ozgur K, Isikoglu M (2005) Cornual heterotopic pregnancy: conservative treatment with transvaginal embryo reduction. Arch Gynecol Obstet 271(1):73-75

20. Oyawoye S, Chander B, Pavlovic B, Hunter J, Gadir AA (2003) Heterotopic pregnancy: successful management with aspiration of cornual/interstitial gestational sac and instillation of small dose of methotrexate. Fetal Diagn Ther 18(1):1-4

21. Ghazeeri GS, Phillips OP, Emerson DS, Kutteh WH, Ke RW (2002) Live birth after treatment of a heterotopic cornual pregnancy with fetal intrathoracic KCI. A case report. J Reprod Med 47(12):1038-1040

22. Sills ES, Perloe M, Kaplan CR, Sweitzer CL, Morton PC, Tucker MJ (2002) Uncomplicated pregnancy and normal singleton delivery after surgical excision of heterotopic (cornual) pregnancy following in vitro fertilization/embryo transfer. Arch Gynecol Obstet 266(3):181-184

23. van der Weiden RM, Brandenburg H (2001) Cornual heterotopic pregnancy: contemporary management options. Am J Obstet Gynecol 185(2):522

24. Sherer DM, Scibetta JJ, Sanko SR (1995) Heterotopic quadruplet gestation with laparoscopic resection of ruptured interstitial pregnancy and subsequent successful outcome of triplets. Am J Obstet Gynecol 172(1 Pt 1):216-217

25. Vilos GA (1995) Laparoscopic resection of a heterotopic cornual pregnancy followed by term vaginal delivery. J Am Assoc Gynecol Laparosc 2(4):471-473 